\title{
Note
}

\section{Value Added per Worker, Capital Accumulation, and Technical Progress}

\author{
HOON HIAN TECK*
}

\begin{abstract}
Within the context of industrial restructuring, it is not unçmmon to use terms such as 'higher value-added per worker', or 'low or high value added activities', and 'high technology' industries. The present note attempts to use the theoretical work in the field of international trade to sharpen our understanding of the relationships among the concepts of value added per worker, capital accumulation, and technical progress. We show that for a large country, capital accumulation raises the real value added per worker in both industries. With neutral technical progress occurring in the L-intensive industry, it is possible for the terms of trade effect to lead to a decline in real labour productivity.
\end{abstract}

\section{INTRODUCTION}

Within the context of industrial restructuring, it is not uncommon to use terms such as 'higher value added per worker', or 'low or high value added activities', and 'high-technology industries'. Generally, it is suggested that the low value added activities should be phased out while policies should be aimed at attracting the high value added activities and high-technology industries into the economy. To date, however, no formal application has been made of the theoretical work in the field of international trade to sharpen our understanding of the relationships among the concepts of value added per worker, capital accumulation and technical progress. It is this task that the present note aims to fulfil.

In Section II, we analyze, within the context of the Hecksher-Ohlin-Samuelson model, the relationships between value added per worker and capital accumulation on the one hand, and value added per worker and technical progress, on the other. ${ }^{1}$ Section III concludes the note.

*The author is Senior Tuitor of Economic at the Department of Economics and Statistics, National University of Singapore. The paper has benefited from comments by Prof. Ronold Jones. Any errors and omissions are, however, solely the author's responsibility.

${ }^{1}$ We will consider only neutral technical progress in the present note. 


\section{VALUE ADDED PER WORKER, CAPITAL ACCUMULATION, \\ AND NEUTRAL TECHNICAL PROGRESS}

In what follows, we assume there are two tradable goods, $\mathrm{X}$ (clothing) and $Y$ (electronics), and two factors, $K$ (capital) and $L$ (labour). Let $X$ be $L$-intensive, and $Y$ be $K$-intensive. There are constant returns to scale in the production of both goods, and there is no factor intensity reversal.

Now, by national income accounting, the total value added, say, in industry $X$, is equal to the value of final goods produced in industry $X$, and also equal to the total returns to factors of production $K$ and $L$, employed in the industry. We may write

$$
\begin{array}{lll}
v a_{x}=\frac{1}{a L x}=W+R k_{x} & \ldots & \ldots \\
v a_{y}=\frac{1}{p a L_{y}}=W+R k_{y} & \ldots & \ldots
\end{array}
$$

where $\quad v a_{j}=$ Value added per worker in industry $j,(j=x, y)$ measured in units of good $X$;

$a_{L j}=$ Labour requirements per unit of output $j,(j=x, y)$;

$k_{j}=$ Capital/labour ratio in industry $j,(j=x, y)$;

$W=$ Real wages measured in units of good $X$;

$R=$ Rental rates measured in units of good $X$; and.

$p=$ Relative price of $\operatorname{good} X, \frac{P_{x}}{P_{y}}$.

By virtue of the fact that we are assuming constant returns to scale, the inputoutput coefficients $\left(a_{i j}, i=K, L ; j=x, y\right)$ are solely dependent upon the prevailing wage/rental ratio, $w$, and technical progress (which we assume to be neutral), $t$. On the other hand, the wage/rental ratio is dependent upon the relative price of good $X$, $p$, as well as technical progress. Hence, we may write the following two equations:

$$
\begin{aligned}
& \frac{d a_{i j}}{d p}=\frac{\partial a_{i j}}{\partial \omega} \frac{\partial \omega}{\partial p} \\
& \frac{d a_{i j}}{d t}=\frac{\partial a_{i j}}{\partial t}+\frac{\partial a_{i j}}{\partial \omega} \frac{\partial \omega}{\partial t}
\end{aligned}
$$

Now, suppose that capital accumulation occurs in this economy. By the Rybczynski theorem, industry $Y$ ( $K$-intensive) expands while industry $X$ ( $L$-intensive) declines, both relatively and absolutely. If the economy faces given prices, the optimal input-output coefficients remain unchanged so that $v a_{x}$ and $v a_{y}$ remain unchanged. However, workers from the $L$-intensive industry have shifted into the $K$-intensive industry so that the national weighted average value added per worker must rise.
However, if the growing economy is large, so that it is able to influence world prices, $p$ may in fact rise. Then, by Equation (3), ${ }^{2}$

$$
\frac{\partial a_{L j}}{d p}=\frac{\partial a_{L j}}{\partial \omega} \frac{\partial \omega}{\partial p}<0
$$

By Equation (1), $v a_{x}$ unambiguously rises. $v a_{y}$ may, however, fall since the relative price of $\operatorname{good} X, p$, has risen. A necessary and sufficient condition for $v a_{y}$ to rise is $\frac{\theta k y}{\theta k y-\theta k x} \sigma y>1$, where $\theta_{k j}$ is capital's distributive share in industry $j$, and $\sigma y$ is the elasticity of substitution between capital and labour in industry $Y^{3,4}$. A value of $\partial y \geqslant 1$ is, however, sufficient to ensure the improvement in the real labour productivity of labour in industry $Y$.

Next, consider the effect of neutral technical progress occurring in industry $X$ ( $L$-intensive). By Equation (4). ${ }^{5}$

$$
\frac{d a_{L j}}{d t}=\frac{\partial a_{L j}}{\partial t}+\frac{\partial a_{L j}}{\partial \omega}+\frac{\partial \omega}{\partial t}<0
$$

Hence, if the economy is small, $v a_{x}$ must unambiguously rise. The labour-output coefficient declines both on account of the technical progress, as well as the rise in wage/rental ratio (required to maintain commodity price ratio), $v a$ also unambiguously rises.

If the country is able to influence world prices, it is conceivable that $p$ may fall sufficiently to cause real value added per worker in the growing industry to decline just like immiserizing growth. The necessary and sufficient condition for this to occur in industry $X$ is somewhat more complicated, supposing that $\pi_{x}$ measures the

$$
2 \frac{\partial a_{L j}}{\partial \omega}<0, \frac{\partial \omega}{\partial p}>0 \text {, so that } \frac{d a_{L j}}{d p}<0 .
$$

${ }^{3}$ We let " " denote proportionate change.

${ }^{4} v a_{y}$ rises if and only if $\hat{p}+\hat{a}_{L y}<0$. But $\hat{a}_{L y}=\frac{-\theta_{k y}}{\theta k y-\theta k x} \sigma y \hat{p}$.

when $\hat{p}>0, v a_{y}$ rises if and only if $\frac{\theta_{k y}}{\theta k y-\theta k x} \sigma y>1$ However, since the coefficient of $\sigma y$ is $>1$, a sufficient condition for $v a_{y}$ to rise is that $\sigma y \geqslant 1$.

$$
\text { s } \frac{\partial a_{L j}}{\partial t}<0, \frac{\partial a_{L j}}{\partial \omega}<0, \frac{\partial \omega}{\partial t}>0 \text {, so that } \frac{d a_{L j}}{d t}<0 .
$$


relative amount of Hick's neutral technical progress, (see Jones, 1965), $v a_{x}$ falls if and only if

$$
\hat{p}<-\left\{1+\frac{1}{\frac{\theta_{k x}}{\theta_{k y}-\theta_{k x}} \alpha x}\right\} \pi_{x}{ }^{6}
$$

Finally, suppose that neutral technical progress occurs in industry $Y(K$ intensive). Then, it is not clear whether the labour-output coefficient will rise or fall. ${ }^{7}$ It depends upon the relative strengths of the first and second terms in Equation (4), which now take opposite signs. That is, while the labour-output coefficient in industry $Y$ declines by virtue of neutral technical progress occurring, the decline in the wage/ rental ratio (required to maintain the same commodity terms of trade) leads to an increase in the labour-output ratio.

The real value added per worker in industry $X$ will, nevertheless, unambiguously decline since labour has become relatively cheaper. Hence, neutral technical progress in the $K$-intensive industry can hurt the real labour productivity in the $L$ intensive industry.

\section{CONCLUSIONS}

Within the $2 \times 2 \times 2$ model, we showed that in the process of capital accumulation, the national weighted average level of real value added per worker rises - a result that follows from the Rybczynski (1955) theorem. If the country is large, however, there is presumption for the real value-added per worker in the $L$-intensive industry to rise.

With neutral technical progress occurring in the $L$-intensive industry, the real value added per worker in both the $K$ - and $L$ - intensive industries will rise. For a large country, however, it is conceivable that the terms of trade effect may lead to a decline in the value-added per worker in the growing industry.

$$
\begin{aligned}
& { }^{6} v a_{x} \text { falls if and only if } \hat{a}_{L x}>0 \text {. But } \hat{a}_{L x}=\frac{-\theta_{k x}}{\theta_{k y}-\theta_{k x}} \sigma x\left(\hat{p}+\pi_{x}\right)-\pi_{x} . \\
& \text { Hence, } v a_{x} \text { falls if and only if } \hat{p}<-\left\{1+\frac{1}{\frac{\theta_{k x}}{\theta_{k y}-\theta_{k x}} \sigma x}\right) \pi_{x} \text {. } \\
& { }^{7} \text { While } \frac{\partial a_{L j}}{\partial t}<0 \text {, and } \frac{\partial a_{L j}}{\partial \omega}<0, \frac{\partial \omega}{\partial t}<0
\end{aligned}
$$

\section{REFERENCES}

Jones, R. W. (1965). “The Structure of Simple General Equilibrium Models”. Journal of Political Economy. Vol. 73.pp. 557-572.

Rybczynski, T. M. (1955). "Factor Endowment and Relative Commodity Prices". Economica. Vol.22 pp. 366. 